\title{
Influência do Solo na Corrosão de Hastes de Âncora Utilizadas no Estaiamento de Redes Elétricas.
}

\author{
Anderson Millano de Sousa Fernandes* (Graduando em Ciência e Tecnologia na Universidade Federal Rural do \\ Semi-Árido - UFERSA) \\ Anderson Nunes Silva (Graduando em Ciência e Tecnologia na Universidade Federal Rural do Semi-Árido - \\ UFERSA) \\ André Moreira de Oliveira (Prof. do curso de Ciência e Tecnologia na Universidade Federal Rural do Semi- \\ Árido - UFERSA) \\ Daniel Freitas Freire Martins (Prof. do curso de Ciência e Tecnologia na Universidade Federal Rural do Semi- \\ Árido - UFERSA) \\ *E-mail: amsf_1990@hotmail.com
}

\section{Resumo:}

Por muitas décadas se faz o uso do revestimento de zinco sobre o aço, alcançado através de galvanização por imersão a quente, para protegê-lo da corrosão em suas diversas aplicações, pois de acordo com a utilização do aço galvanizado, vários quesitos devem ser analisados para uma maior eficiência e segurança nos projetos. Com isso, estudos são realizados nessa área com a finalidade de ampliar a vida útil das peças, reduzindo os custos com manutenção e substituição delas. Sabe-se que a corrosão de estruturas enterradas pode ser causada tanto pelas propriedades físico-químicas e biológicas do solo, como por fatores externos. São diversos os fatores que contribuem para a corrosividade dos solos. Dentre estes se incluem o tipo de solo, suas características estruturais, permeabilidade, teor de umidade, grau de aeração, conteúdo de sais solúveis, acidez e presença de micro-organismos. Para tornar o meio ainda mais complexo, alguns destes fatores são interrelacionados. Neste trabalho foram selecionados 10 postes e realizaram-se quatro coletas dos solos, com um intervalo de 30 dias de uma para outra, com a utilização de um trado holandês. As porções obtidas foram armazenadas em sacos plásticos, as quais foram levadas ao laboratório para realização das análises físico-químicas necessárias. No laboratório as amostras foram secadas, destorroadas, separadas nas frações do solo por tamização e homogeneização da fração $<2 \mathrm{~mm}$, assim denominada "terra fina seca ao ar" (TFSA), que foi utilizada para os ensaios. Os ensaios feitos foram umidade, condutividade, salinidade, pH, matéria orgânica, sódio, potássio, cálcio, magnésio e RAS. Esses ensaios foram realizados no intuito de verificar quais os principais agressores do solo da região que influenciam na corrosão das hastes. Os principais resultados obtidos foram alto teor de umidade nos solos argilosos, por existir uma maior retenção de água devido à presença de microporos, o que torna esse solo mais agressivo para as hastes do que os demais analisados. As camadas mais superficiais tendem a apresentar cores mais escuras em função do maior teor de matéria orgânica e os solos da região foram encontrados como sendo salino, que é um tipo de solo prejudicial às estruturas metálicas devido ao alto teor de sais e baixa resistividade elétrica.

Palavras-chave:

Aço galvanizado; análises físico-químicas; salinidade; sais solúveis. 


\section{I NTRODUÇÃO}

O processo industrial de obtenção do aço ocorreu no século XIX, desde então vem aumentando em grande escala a quantidade disponível no mercado. Por esse motivo, o aço tornou-se importante no desenvolvimento mundial, já que é utilizado nos principais segmentos econômicos da sociedade (A FABRICAÇÃO, 2014). Desta forma, se fez necessário à utilização das formas de proteção do mesmo, como a galvanização, o revestimento do ferro ou aço com zinco, é possivelmente o processo mais ecológico de prevenção contra a corrosão. Pois se estima que os custos com corrosão representem cerca de $4 \%$ do PIB das nações industrializadas, percentual que tende a ser maior na economia dos países emergentes (INSTITUTO DE METAIS NÃO FERROSOS, 2012).

Há uma preocupação maior com relação à corrosão - deterioração dos materiais pela ação química ou eletroquímica do meio, podendo estar ou não associado a esforços mecânicos (OLIVEIRA, 2008). Esse problema, por sua vez, desperta interesse de descobrir as melhores formas de proteção para os metais, com a intenção de diminuir a sua produção primária e aumentar a vida útil, reduzindo assim os custos com a manutenção, substituição das peças e a degradação do meio ambiente devido à retirada dos minérios.

O solo é formado pelas fases sólida, líquida e gasosa, sendo a primeira composta por partículas de diversos tamanhos minerais, raízes de plantas, populações de macro e microrganismos e suas enzimas. Assim, o conjunto de todos os componentes da fase sólida leva a formação de micro-habitats ou micro-sítios. Com características singulares, o solo atua como um dreno para contaminantes e, também, como tampão natural, que controla o transporte de elementos químicos e outras substâncias para a atmosfera, hidrosfera e biota (MOREIRA e SIQUEIRA, 2006, OTENIO et., al 2005). Devido à complexidade deste meio, se fez necessário um estudo da influência do solo na corrosão aço que se encontra em contato com o mesmo, o que foi feito por meio de análises físico-químicas, que permitam entender a influência do solo neste fenômeno.

Desta forma, este trabalho teve como objetivo estudar a influência do solo na corrosão de hastes de âncora utilizadas no estaiamento de redes elétricas entre os munícipios de Caraúbas e Governado Dix-Sept Rosado no Estado do Rio Grande do Norte visando à escolha da melhor forma de proteção a ser utilizada. O trabalho pode conter imagens, tabelas, citações, e devem seguir os estilos aqui apresentados, de forma a obtermos um resultado homogêneo entre os trabalhos ao final do processo, possibilitando a confecção dos anais da melhor maneira possível.

\section{MATERI AL E MÉTODOS}

Para a realização do trabalho selecionou-se previamente 10 pontos (Figura 1) localizados entre as cidades de Caraúbas e Governador Dix-Sept Rosado, ambas no estado do Rio Grande do Norte, tomando o cuidado de registrar o ambiente de instalação de cada um através de fotos e etiquetas.

As coletas dos solos tiveram um intervalo de 30 dias entre elas, no total de quatro coletas e foram feitas nos dias 02/06/15, 02/07/15, 02/08/15 e 02/09/15. Para a coleta das amostras utilizou-se um trado holandês, para as perfurações de profundidade igual a $20 \mathrm{~cm}$. As porções obtidas ficaram armazenadas em sacos plásticos, os quais foram levados para o laboratório para a realização das análises físicoquímicas necessárias como: umidade, condutividade, salinidade, pH, matéria orgânica, sódio, potássio, cálcio, magnésio e RAS, que estão descritas a seguir: 


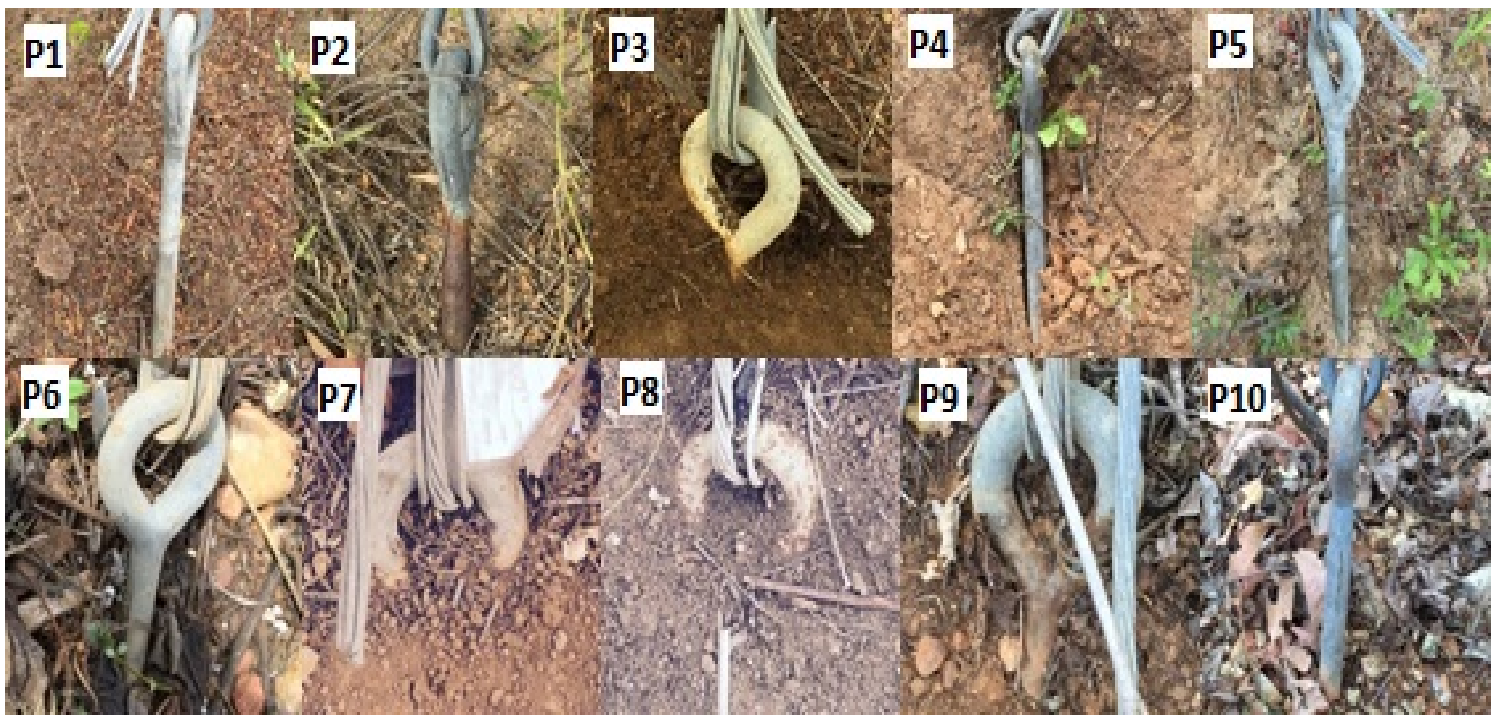

Figura 1:Hastes de âncora utilizadas neste trabalho e aspectos do local onde se encontram.

Preparo da amostra: As amostras coletadas foram secas ao ar livre, em ambiente ventilado e seco, após a secagem foram identificadas e espalhadas para o processo de destorroamento, que acontece colocando o solo sobre uma superfície plana, separando para um lado a fração grosseira, pressionado manualmente com um rolo de madeira até desfazer os torrões maiores, com o cuidado para não quebrar pedras ou concreções. Os solos separados nas frações por tamização e homogeneização da fração $<2$ mm são denominados "terra fina seca ao ar" (TFSA), que foram usados nos ensaios (EMBRAPA, 1997).

2.1 Umidade: Foi colocado 50,0 gramas das amostras, em béqueres numerados e previamente tarados. Após a pesagem os solos foram transferidos para estufa a $105^{\circ} \mathrm{C}$, deixados nesta condição durante 24 horas. Em seguida, retirados da mesma, colocados no dessecador para esfriar e pesados novamente. Por fim calculou-se a variação do peso inicial e final, calculando com a equação 1 o teor percentual da umidade (EMBRAPA, 1997).

$$
\text { (Massa de água*100)/(Massa da amostra) }
$$

2.2 Condutividade: A condutividade foi feita por meio de eletrodo combinado imerso em suspensão do solo após adição de água. Para este ensaio foi depositado $10 \mathrm{~cm}^{3}$ de solo em copo plástico e adicionado $25 \mathrm{ml}$ de água destilada, homogeneizado com bastão de vidro e deixado em repouso por uma hora. O próximo passo foi mergulhar os eletrodos na suspensão em repouso medindo a condutividade, usando um Condutivimetro (MS TECNOPON INSTRUMENTAÇÃO) devidamente calibrado. (EMBRAPA, 1997).

2.3 pH: Para medir o pH da solução utilizou um potenciômetro por meio de eletrodo combinado imerso do solo após adição de água. Para este ensaio foi depositado $10 \mathrm{~cm}^{3}$ de solo em copo plástico e adicionado $25 \mathrm{ml}$ de água destilada, homogeneizado com bastão de vidro e deixado em repouso por uma hora. Homogeneizando novamente antes de mergulhar o eletrodo na suspensão, obtendo a leitura do pH no Potenciômetro com eletrodo combinado (PHMETER JKPHM-005) devidamente calibrado.

2.4 Matéria Orgânica: Colocou-se $5 \mathrm{~g}$ das amostras em cadinhos de porcelana numerados e previamente tarados, levado para mufla a $500{ }^{\circ} \mathrm{C}$ deixados nesta condição durante três horas. Depois de retirados da mufla foram colocados para esfriar no dessecador. Por último, pesados novamente e usando a equação 2 cálculou-se, teor de matéria orgânica (EMBRAPA, 1997). 
2.5 Sódio e Potássio Trocável: A solução extratora de Mehlich 1, também chamada de solução duplo-ácida ou de Carolina do Norte, é constituída por uma mistura de $\mathrm{HCl} 0,05 \mathrm{M}+\mathrm{H}_{2} \mathrm{SO}_{4}$ 0,0125M. Na extração coloca-se $10 \mathrm{~cm}^{3}$ de TFSA em erlenmeyer de $125 \mathrm{ml}$ e adiciona $100 \mathrm{ml}$ de solução extratora duplo-ácida (HCI 0,05M + $\mathrm{H}_{2} \mathrm{SO} 4$ 0,0125M). Agita-se durante cinco minutos em um agitador horizontal circular. Deixar decantar durante uma noite. Utiliza-se uma parte do extrato $(20 \mathrm{ml})$ que foi reservada para as determinações do sódio e potássio, antes de proceder à leitura da amostra, o fotômetro deve se calibrado utilizando soluções padrão de Na e K. Após a calibração leva-se o extrato ao fotômetro de chama. Efetuar a leitura na escala do aparelho. No caso da leitura ultrapassar o limite de detecção do aparelho, proceder às diluições necessárias (EMBRAPA, 1997).

2.6 Cálcio e magnésio trocáveis: Pesa-se $10 \mathrm{~cm}^{3}$ de solo, colocar em erlenmeyer de $250 \mathrm{ml}$ e adicionar $100 \mathrm{ml}$ de solução de $\mathrm{KCl} 1,0 \mathrm{M}$. Agitando com movimentos circulares por 5 minutos, depois da agitação, deixar em repouso durante uma noite. Após o tempo em repouso pipetar o sobrenadante para erlenmeyer de $200 \mathrm{ml}$. Para determinação do cálcio + magnésio, transferir 25 $\mathrm{mL}$ do extrato $\mathrm{KCl}$ 1,0 M para um erlenmeyer de $250 \mathrm{~mL}$. Adicionar $4 \mathrm{~mL}$ do coquetel tampão e uma pitada do indicador Negro de eriocromo T e titular com a solução de EDTA 0,0125 M, até viragem da cor rósea para azul puro ou esverdeada (com esta titulação são determinados conjuntamente $\mathrm{Ca}^{2+} \mathrm{e} \mathrm{Mg}^{2+}$ ) e anotar o volume de EDTA gasto. Após isso se realiza os cálculo necessário com a seguinte expressão: $\mathrm{Ca}^{2+}+\mathrm{Mg}^{2+}(\mathrm{cmolc} / \mathrm{kg})=\operatorname{mL}$ EDTA (EMBRAPA, 1997).

2.7 Cálcio trocável: Pesa-se $10 \mathrm{~cm}^{3}$ de solo, colocar em erlenmeyer de $250 \mathrm{ml}$ e adicionar $100 \mathrm{ml}$ de solução de KCl 1,0 M. Agitando com movimentos circulares por 5 minutos, depois da agitação, deixar em repouso durante uma noite. Após o tempo em repouso pipetar o sobrenadante para erlenmeyer de 200ml. Para determinação do cálcio, transferir $25 \mathrm{~mL}$ do extrato $\mathrm{KCl} 1,0 \mathrm{M}$ para um erlenmeyer de $250 \mathrm{~mL}, 2 \mathrm{~mL}$ de $\mathrm{KOH}$ a $10 \%$ e uma pitada de Calcon. Realiza uma titulação complexométrica com solução de EDTA 0,0125 M até viragem da cor rósea para azul. Anotar o volume de EDTA gasto, que corresponde ao cálcio existente. Por fim calcula-se a percentagem de cálcio na amostra de solo de acordo com a seguinte expressão: $\mathrm{Ca}^{2+}(\mathrm{cmolc} / \mathrm{kg})=\mathrm{mL}$ EDTA (EMBRAPA, 1997).

2.8 Magnésio trocável: Diferença entre a quantidade de EDTA utilizada na titulação de $\mathrm{Ca}^{2+}+\mathrm{Mg}^{2+}$ e na titulação $\mathrm{Ca}^{2+}$ é o valor correspondente ao $\mathrm{Mg}^{2+}$ (EMBRAPA, 1997).

2.9 A RAS foi calculada com a equação 3 a partir das quantidades de Na, ca e Mg. e relacionada com o pH e a condutividade elétrica, para a classificação dos solos analisados. (MONTEIRO; SILVA; LÔBO, 2009)

$$
\text { RAS }=\mathrm{Na}^{+} / \sqrt{ }\left(\mathrm{Ca}^{2+}+\mathrm{Mg}^{2+}\right) / 2
$$

\section{RESULTADOS E DISCUSSÃO}

Na finalidade de adquirir mais dados e conhecimentos sobre os solos da região, foram realizadas quatro coletas em cada ponto com um intervalo de 30 dias entre elas. Observando-se os dados apresentados pode-se constatar que as propriedades dos solos coletados nos 10 pontos são distintas, com variações, significativas, nos parâmetros analisados o que concorda com o aspecto visual dos mesmos (Figura 1). Todos os resultados obtidos a partir das análises físico-químicas se encontram na Tabela 1.

Tabela 1 - Resultados das análises de todos os parâmetros medidos. 


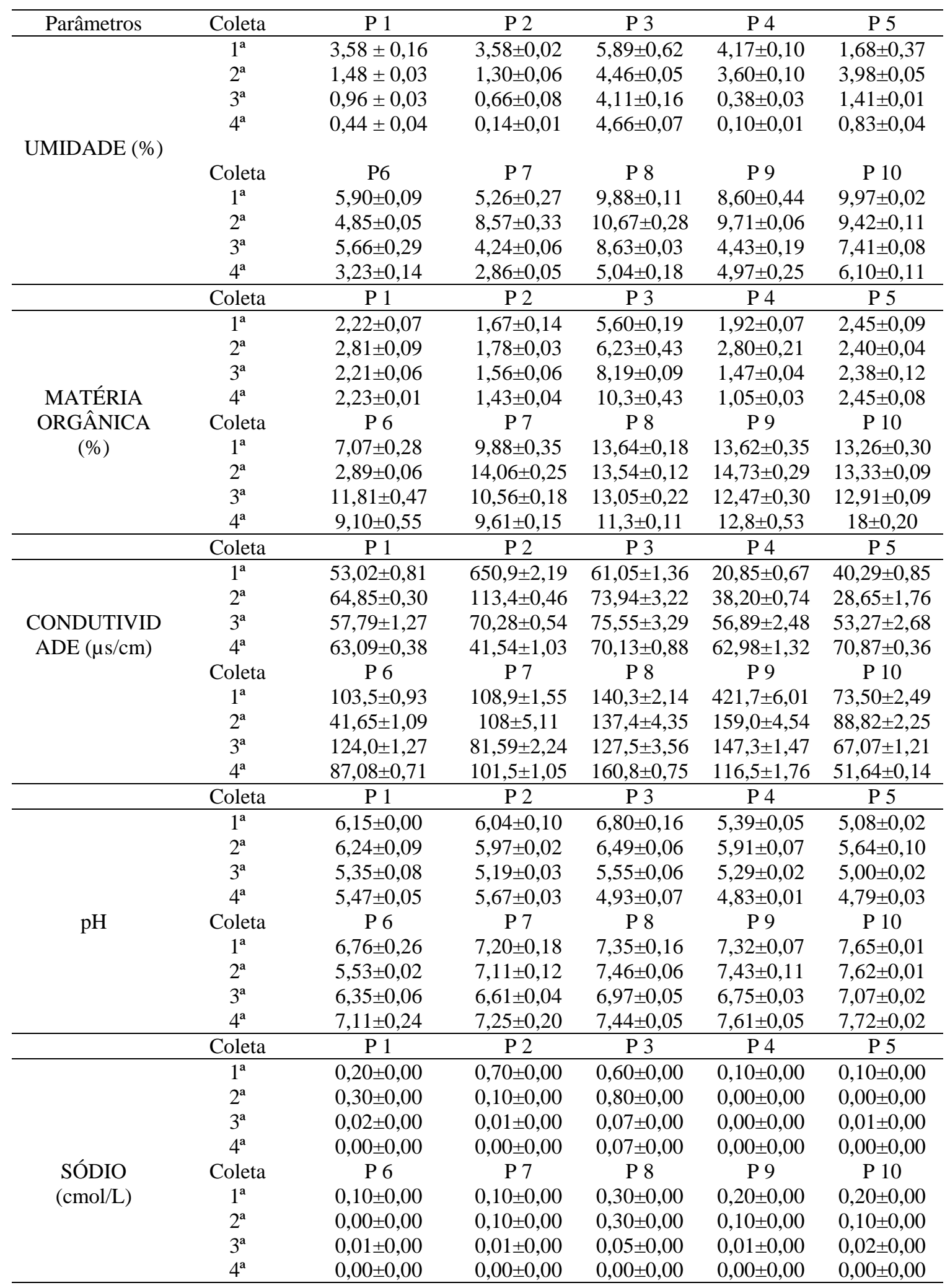

Tabela 1 - Resultados das análises de todos os parâmetros medidos. (Continuação) 


\begin{tabular}{|c|c|c|c|c|c|c|}
\hline & Coleta & P 1 & P 2 & P 3 & P 4 & P 5 \\
\hline \multirow{9}{*}{$\begin{array}{l}\text { CÁLCIO } \\
(\mathrm{cmol} / \mathrm{L})\end{array}$} & $1^{a}$ & $3,80 \pm 0,00$ & $7,20 \pm 0,92$ & $13,6 \pm 0,64$ & $5,25 \pm 0,35$ & $3,53 \pm 0,12$ \\
\hline & $2^{a}$ & $5,00 \pm 0,00$ & $4,00 \pm 0,00$ & $12,5 \pm 0,06$ & $1,43 \pm 0,06$ & $1,97 \pm 0.06$ \\
\hline & $3^{a}$ & $3,00 \pm 0,00$ & $2,50 \pm 0,00$ & $16,0 \pm 0,00$ & $0,90 \pm 0,00$ & $3,10 \pm 0.00$ \\
\hline & $4^{\mathrm{a}}$ & $1,73 \pm 0,05$ & $1,26 \pm 0,05$ & $11,4 \pm 0,05$ & $0,46 \pm 0,05$ & $1,00 \pm 0,00$ \\
\hline & Coleta & P 6 & P 7 & P 8 & P 9 & P 10 \\
\hline & $1^{\mathrm{a}}$ & $19,0 \pm 0,15$ & $19,6 \pm 0,29$ & $39,3 \pm 0,26$ & $25,8 \pm 0,23$ & $22,3 \pm 0,25$ \\
\hline & $2^{a}$ & $0,83 \pm 0,06$ & $13,9 \pm 0,06$ & $31,6 \pm 0,29$ & $25,4 \pm 0,10$ & $22,9 \pm 0,06$ \\
\hline & $3^{a}$ & $21,6 \pm 0,00$ & $15,1 \pm 0,00$ & $32,5 \pm 0,00$ & $18,6 \pm 0,00$ & $23,5 \pm 0,00$ \\
\hline & $4^{\mathrm{a}}$ & $12,6 \pm 0,05$ & $8,20 \pm 0,00$ & $20,1 \pm 0,05$ & $13,5 \pm 0,00$ & $12,5 \pm 0,00$ \\
\hline \multirow{11}{*}{$\begin{array}{l}\text { MAGNÉSIO } \\
(\mathrm{cmol} / \mathrm{L})\end{array}$} & Coleta & P 1 & P 2 & P 3 & P 4 & P 5 \\
\hline & $1^{\mathrm{a}}$ & $2,37 \pm 0,06$ & $1,70 \pm 0,57$ & $4,80 \pm 0,66$ & $0,23 \pm 0,06$ & $3,87 \pm 0,35$ \\
\hline & $2^{\mathrm{a}}$ & $1,67 \pm 0,12$ & $1,83 \pm 0,06$ & $9,43 \pm 0,06$ & $1,93 \pm 0,12$ & $2,07 \pm 0,12$ \\
\hline & $3^{\mathrm{a}}$ & $4,40 \pm 0,00$ & $4,40 \pm 0,00$ & $10 \pm 0,00$ & $2,10 \pm 0,00$ & $3,10 \pm 0,00$ \\
\hline & $4^{\mathrm{a}}$ & $0,26 \pm 0,05$ & $3,26 \pm 0,05$ & $18,9 \pm 0,05$ & $1,50 \pm 0,00$ & $4,96 \pm 0,05$ \\
\hline & Coleta & P 6 & P 7 & P 8 & P 9 & P 10 \\
\hline & $1^{\mathrm{a}}$ & $2,07 \pm 0,15$ & $2,23 \pm 0,68$ & $8,03 \pm 0,47$ & $3,40 \pm 0,20$ & $3,57 \pm 0,15$ \\
\hline & $2^{\mathrm{a}}$ & $1,13 \pm 0,06$ & $1,77 \pm 0,06$ & $11,1 \pm 0,15$ & $2,27 \pm 0,01$ & $2,13 \pm 0,15$ \\
\hline & $3^{a}$ & $3,40 \pm 0,00$ & $2,00 \pm 0,00$ & $12,3 \pm 0,00$ & $2,40 \pm 0,00$ & $4,20 \pm 0,00$ \\
\hline & $4^{\mathrm{a}}$ & $14,2 \pm 0,05$ & $11,5 \pm 0,05$ & $26,4 \pm 0,00$ & $16,4 \pm 0,05$ & $14,0 \pm 0,00$ \\
\hline & Coleta & P 1 & P 2 & P 3 & P 4 & P 5 \\
\hline \multirow{10}{*}{$\begin{array}{c}\text { POTÁSSIO } \\
(\mathrm{cmol} / \mathrm{L})\end{array}$} & $1^{\mathrm{a}}$ & $0,20 \pm 0,00$ & $0,30 \pm 0,00$ & $0,20 \pm 0,00$ & $0,30 \pm 0,00$ & $0,30 \pm 0,00$ \\
\hline & $2^{\mathrm{a}}$ & $0,50 \pm 0,00$ & $0,20 \pm 0,00$ & $0,20 \pm 0,00$ & $0,50 \pm 0,00$ & $0,20 \pm 0,00$ \\
\hline & $3^{a}$ & $0,18 \pm 0,00$ & $0,19 \pm 0,00$ & $0,30 \pm 0,00$ & $0,17 \pm 0,00$ & $0,31 \pm 0,00$ \\
\hline & $4^{\mathrm{a}}$ & $0,16 \pm 0,00$ & $0,11 \pm 0,00$ & $0,22 \pm 0,00$ & $0,08 \pm 0,00$ & $0,28 \pm 0,00$ \\
\hline & Coleta & P 6 & P 7 & P 8 & P 9 & P 10 \\
\hline & $1^{\mathrm{a}}$ & $0,10 \pm 0,00$ & $0,50 \pm 0,00$ & $0,10 \pm 0,00$ & $0,40 \pm 0,00$ & $1,00 \pm 0,00$ \\
\hline & $2^{\mathrm{a}}$ & $0,30 \pm 0,00$ & $0,50 \pm 0,00$ & $0,10 \pm 0,00$ & $0,40 \pm 0,00$ & $0,50 \pm 0,00$ \\
\hline & $3^{a}$ & $0,20 \pm 0,00$ & $0,48 \pm 0,00$ & $0,08 \pm 0,00$ & $0,43 \pm 0,00$ & $0,49 \pm 0,00$ \\
\hline & $4^{\mathrm{a}}$ & $0,12 \pm 0,00$ & $0,33 \pm 0,00$ & $0,14 \pm 0,00$ & $0,47 \pm 0,00$ & $0,49 \pm 0,00$ \\
\hline & Coleta & P 1 & $\mathrm{P} 2$ & P 3 & P 4 & P 5 \\
\hline \multirow{9}{*}{ RAS } & $1^{\mathrm{a}}$ & $0,04 \pm 0,00$ & $0,12 \pm 0,00$ & $0,07 \pm 0,00$ & $0,02 \pm 0,00$ & $0,02 \pm 0,00$ \\
\hline & $2^{a}$ & $0,06 \pm 0,00$ & $0,02 \pm 0,00$ & $0,09 \pm 0,00$ & $0,00 \pm 0,00$ & $0,00 \pm 0,00$ \\
\hline & $3^{a}$ & $0,00 \pm 0,00$ & $0,00 \pm 0,00$ & $0,00 \pm 0,00$ & $0,00 \pm 0,00$ & $0,00 \pm 0,00$ \\
\hline & $4^{\mathrm{a}}$ & $0,00 \pm 0,00$ & $0,00 \pm 0,00$ & $0,07 \pm 0,00$ & $0,00 \pm 0,00$ & $0,00 \pm 0,00$ \\
\hline & Coleta & P 6 & P 7 & P 8 & P 9 & P 10 \\
\hline & $1^{\mathrm{a}}$ & $0,01 \pm 0,00$ & $0,01 \pm 0,00$ & $0,02 \pm 0,00$ & $0,02 \pm 0,00$ & $0,02 \pm 0,00$ \\
\hline & $2^{a}$ & $0,00 \pm 0,00$ & $0,01 \pm 0,00$ & $0,02 \pm 0,00$ & $0,01 \pm 0,00$ & $0,01 \pm 0,00$ \\
\hline & $3^{a}$ & $0,00 \pm 0,00$ & $0,00 \pm 0,00$ & $0,00 \pm 0,00$ & $0,00 \pm 0,00$ & $0,00 \pm 0,00$ \\
\hline & $4^{\mathrm{a}}$ & $0,00 \pm 0,00$ & $0,00 \pm 0,00$ & $0,00 \pm 0,00$ & $0,00 \pm 0,00$ & $0,00 \pm 0,00$ \\
\hline
\end{tabular}

Essas variações são percebidas primeiramente na textura dos solos, que se refere à proporção das partículas dos mesmos, determinadas de acordo com suas dimensões (granulometria): areia (mais grosseira); silte (intermediário) e argila (mais fina). Essas características influenciam diretamente no comportamento dos parâmetros analisados.

Um dos problemas com o solo argiloso é a sua permeabilidade lenta resultando em uma grande capacidade de retenção de água. Uma vez que as partículas do solo são pequenas e próximas umas das outras, a água leva muito mais tempo para se mover através dos solos com maior teor de argila do que dos outros tipos de solo (GERARD, 2015).

Nos pontos 8, 9 e 10 do trabalho foi obtido maior teor umidade, pois nesses pontos os solos tem característica argilosa, que é determinante para maior retenção de liquido. Tal fato influência diretamente na intensidade do processo corrosivo. Os solos argilosos são mais corrosivos do que solos arenosos (CASTRO, 2013). Fato esse que merece destaque e pode ser constatado observando-se a figura 1, onde as hastes 8 e 9, em especial, apresentam-se mais corroídas que as demais. Obviamente, outros fatores podem tem influenciado para tal constatação como, por exemplo, o tempo de exposição da peça metálica ao solo. No entanto, como se trata da mesma rede elétrica, possivelmente, o tempo de exposição não deve diferir significativamente. 
O volume de chuvas em uma determinada região, também, tem influência direta na umidade do solo. Assim, de acordo com os valores destes parâmetros, percebe-se a influência decorrente da quantidade de precipitações ocorridas na região. Associando os pontos à estação meteorológica da cidade Apodi-RN (Gráfico 1).

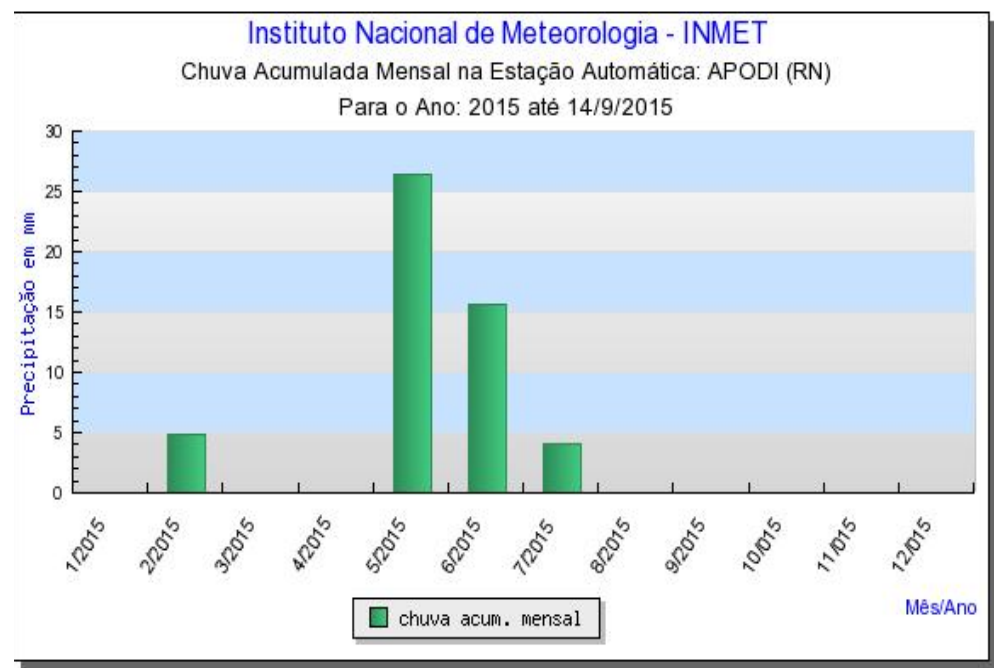

Gráfico 1: Acúmulo de chuvas mensais na cidade de Apodi. Fonte:

http://www.inmet.gov.br/sonabra/pg_iframe.php?codEst=A340\&mesAno=2015

O clima, tipo de material de origem e a deposição do material orgânico na superfície, conferem ao perfil de solo cores diferenciado. Normalmente as camadas mais superficiais, tendem a apresentar cores mais escuras em função do maior teor de matéria orgânica (Andreoli; Andreoli; Justi Junior, 2014).

A matéria orgânica inclui sementes, folhas, raízes, minhocas e estrume, bem como as bactérias, fungos e húmus. A estrutura do solo é altamente dependente do teor de matéria orgânica, particularmente em solos de textura argilosos e arenosos. Quanto maior for à quantidade de matéria orgânica, melhor será a estrutura do solo. A matéria orgânica tende a se concentrar na parte superior do solo, uma vez que este é o lugar onde ocorre a produção de plantas. Essas se deterioram tornando-se um material escuro chamado húmus. Este é o responsável pela cor mais escura do solo (SOILPAK 2015).

Isso comprova os dados encontrados nas análises, onde os solos mais escuros (Pontos 3 e 6-10) tiveram maior teor de matéria orgânica em relação aos solos de coloração mais clara (Pontos 1, 2, 4 e 5). (Ver gráfico 2).

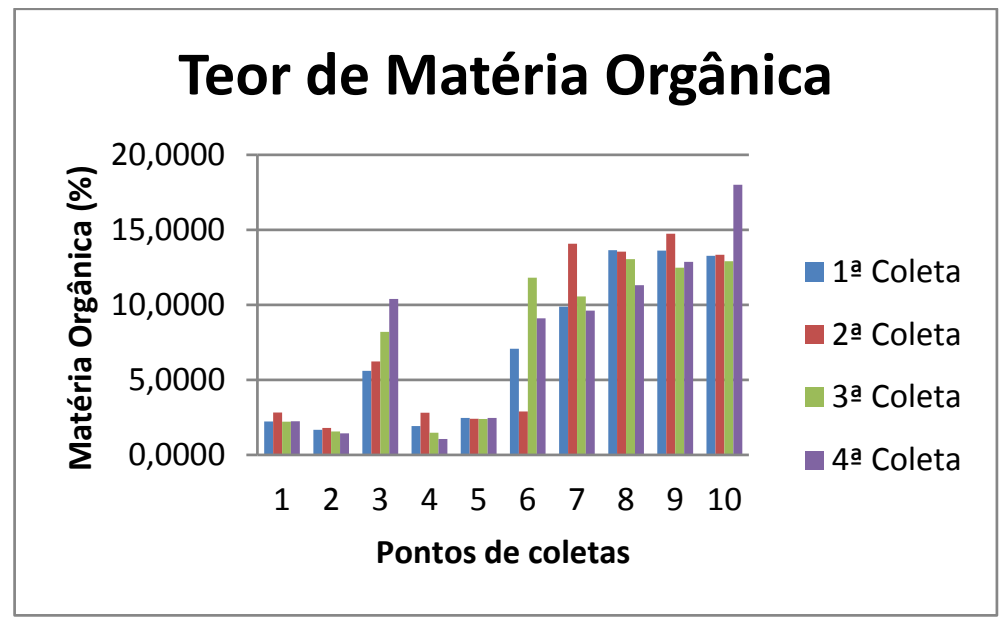

Gráfico 2: Teor de matéria orgânica.

A decomposição da matéria orgânica gera acidez de diversas formas, através de reação de nitrificação, oxidação e geração de $\mathrm{CO}_{2}$. A mineralização dos compostos orgânicos libera compostos de N e S que, ao sofrerem oxidação, podem liberar prótons na solução do solo. A oxidação biológica dos 
compostos orgânicos produz $\mathrm{CO}_{2}$, o qual reage com a água para formar acido carbônico, que se dissocia e acidifica o solo. Aumentando a agressividade do mesmo quanto à corrosão (CASTRO, 2013).

Na região nordestina brasileira onde há presença de solos com baixa resistividade (solos com caráter salino ou sálico) este fato pode ter implicações significativas no projeto e na implantação das linhas de transmissão de energia elétrica e de telecomunicações. Devido ao aspecto relacionado aos processos de corrosão em estruturas metálicas enterradas as quais são bastante influenciadas pela presença de sais. Quanto maior a quantidade de sais, mais elevada sua condutividade elétrica (menor resistividade), consequentemente, maior sua capacidade corrosiva (OLIVEIRA, 2003).

De acordo com A.b. Chance (2003) os solos constituem o ambiente mais complexo conhecido para corrosão metálica. Pois a corrosão dos metais no solo pode variar de relativamente rápida perda de material para efeitos insignificantes. Obviamente, alguns tipos de solos são mais corrosivos do que outros. Devido à origem dos solos, juntamente com o clima, geologia local, vida vegetal e animal, e os efeitos da atividade do homem, influenciam no potencial corrosivo dos solos. A análise química dos solos é normalmente limitada a determinações dos constituintes que são solúveis em água em condições padronizadas. A natureza e a quantidade de sais solúveis, em conjunto com o teor de umidade do solo, em grande parte, determinam a capacidade do solo para conduzir corrente elétrica. Portanto, os solos de grãos finos, tais como argilas e alguns sedimentos são considerados como tendo maior potencial de corrosão, porque eles normalmente têm baixa condutividade hidráulica (COMPANY, 2003).

A partir dos resultados de $\mathrm{pH}$, Condutividade e RAS, as amostras foram classificadas como salinos de acordo com a tabela 2 e essa característica é de um solo prejudicial às estruturas metálica, devido seus altos valores de sais solúveis e baixa resistividade.

Tabela 2 - Classificação dos solos de acordo com o nível de salinidade

\begin{tabular}{lccc}
\hline & & & \\
SOLO & CE (mmhos.cm-1) & RAS $(\%)$ & $\mathrm{pH}$ \\
Normal & $<4$ & $<13$ & $<8,5$ \\
Salino & $>4$ & $<13$ & $<8,5$ \\
Sódico & $<4$ & $>13$ & $>8,5$ \\
Salino/Sódico & $>4$ & $>13$ & $<8,5$ \\
\hline
\end{tabular}

\section{CONCLUSÃO}

Concluem-se dos resultados que a umidade do solo é um fator diretamente influenciado pela quantidade de chuvas na região e que influencia de forma significativa nos resultados dos outros ensaios realizados. Os solos mais argilosos têm maior retenção de líquidos devido a maior proximidade de suas partículas, o que dificulta a passagem da água através de seus poros e torna o ambiente mais agressivo, devido ao maior contato da peça de aço, com a água, variando sua intensidade de acordo com a quantidade de sais dissolvidos. Os solos de cores mais escuras têm essa característica devido ao alto teor de matéria orgânica do meio e essa se deteriora tornando-se um material escuro chamado húmus. Este é o responsável pela cor mais escura do solo. A decomposição da matéria orgânica gera acidez de diversas formas, aumentando a agressividade do mesmo quanto à corrosão. Os solos analisados classificados como salinos, são prejudiciais às estruturas metálicas, devido seus altos valores de salinização e sua baixa resistividade. Desta forma, torna-se necessário o uso de técnicas eficientes de proteção dessas estruturas.

\section{Soil Influence in Corrosion of Anchor Rods Used in Rigging of Electrical Network.}

Abstract: For many decades it makes the use of zinc coating on steel, reached via dip galvanizing hot, to protect it from corrosion in its various applications, since according to the use of galvanized steel, 
several issues should be analyzed for greater efficiency and security in the projects. Thus, studies are carried out in this area in order to extend the life of parts, reducing maintenance costs and replacement of them. It is known that corrosion of buried structures can be caused by both physical-chemical and biological properties of the soil, and by external factors. There are several factors that contribute to the corrosivity of the soil. Among these include soil type, their structural characteristics, permeability, moisture content, degree of aeration, soluble salts content, acidity and the presence of micro-organisms. To make the medium even more complex, some of these factors are interrelated. In this work we selected 10 poles and four were held soil collected at an interval of 30 days from one to another, using a Dutch auger. The portions obtained were stored in plastic bags, which were taken to the laboratory to carry out the necessary physical and chemical analysis. In the laboratory, the samples were dried, destorroadas separated fractions in the soil by wet sieving and homogenizing the fraction $<2 \mathrm{~mm}$, so called "air dried soil" (TFSA), which was used for the tests. The tests were done moisture, conductivity, salinity, $\mathrm{pH}$, organic matter, sodium, potassium, calcium, magnesium and RAS. These tests were conducted in order to verify what are the main perpetrators of the soil in the area that influence the corrosion of the rods. The main results were high moisture content in clay soils, because there is a greater retention of water due to the presence of micropores, which makes this more aggressive soil for the stems than the other analyzed. The superficial layers tend to have darker colors due to the higher organic matter content and soil in the area were found to be saline, which is a type of harmful ground the metallic structures due to the high salt content and low electrical resistivity .

Keywords: galvanized steel; physical and chemical analysis; salinity; soluble salts.

\section{Referências bibliográficas}

A FABRICAÇÃO do aço. 2014. Disponível em: https://esquadraodoconhecimento.wordpress.com/ciencias-da-natureza/quim/a-fabricacao-do-aco/. Acesso em: 25/09/2015

ANDREOLI, Cleverson V.; Andreoli, Fabiana de Nadai; Justi Junior, Jorge. Formação e características dos solos para o entedimento de sua importância agrícola e ambiental. In: Andreoli, Cleverson v.; torres, Patrícia Lupion. Complexidade: redes e conexões do ser sustentável. Curitiba: kairós, 2014. P. 511-529.

ARCELORMITTAL VEGA DO SUL (Santa Catarina). Galvanizados. Disponível em: http://www.vegadosul.com.br/produtos_mercados/galvanizados/galvanizados.asp>. Acesso em: 14 jun. 2015.

CAMARGO, Otávio Antônio de.; MONIZ, Antônio Carlos; JORGE, José Antônio; VALADARES, José Maria Aires da Silva. Métodos de Análise Química, Mineralógica e Física de Solos do Instituto Agronômico de Campinas. Campinas: Instituto Agronômico, 2009. 77 p.

CASTRO, Dênis de Freitas. ESTUDO DA CORROSÃO DO AÇO 1020 NO SOLO NATURAL ARGILOSO DA REGIÃO AMAZÔNICA. 2013. 83f. Dissertação (Pós-Graduação em Engenharia de Recursos) - Faculdade de Tecnologia da Universidade Federal do Amazonas, Manaus.

COMPANY, A.b. Chance. Helical Screw Foundation System Design Manual for New Construction. Shelton, Ct: (c)opyright 2003 Hubbell, Inc, 2003.

EMBRAPA (Rio de Janeiro). Centro Nacional de Pesquisa de Solos. Manual de métodos de análise de solo. 2. Ed. Rio de Janeiro: Embrapa, 1997. 564 p.

FANG, S.J.; ROY, S. AND KRAMER, J. “Transmission Structures” Structural Engineering Handbook Ed. Chen Wai-Fah Boca Raton: CRC Press LLC, 1999..

GENTIL, Vicente. Corrosão. 6. ed. Rio de Janeiro: Grupo Gen - Ltc, 2011. 376 p.

GERARD, Jack. Properties of Clay Soil. Disponível em: <http://homeguides.sfgate.com/propertiesclay-soil-71840.html>. Acesso em: 23 set. 2015.

GOMES, L. P. Diagnóstico de Corrosão e Proteção Catódica em Tubulações Enterradas de Plantas Industriais, Boletim Técnico da IEC - Instalações e Engenharia de Corrosão Ltda, $\mathrm{n}^{\circ}$, IEC-SPD001IT-001, 30p. 2001. 
INSTITUTO DE METAIS NÃO FERROSOS. Guia de galvanização por imersão a quente. ICZ, [20-].

MONTEIRO, G. S. ; SILVA, J. N ; LÔBO, H. L. L. . Estudo Da Razão De Adsorção De Sódio Do Rejeito De Dessalinizadores Implantados No Semiárido Paraibano. Enciclopédia Biosfera, v. 5, p. 01-06, 2009.

SICETEL (São Paulo). ANÁLISE DO MERCADO DO AÇO 2014. São Paulo: Sicetel, 2014. 